\title{
Article
}

\section{Development of MY FRAM matrix to assess food safety risks in horticultural crops}

Soon, Jan Mei and Baines, Richard

Available at http://clok.uclan.ac.uk/14021/

Soon, Jan Mei ORCID: 0000-0003-0488-1434 and Baines, Richard (2015)

Development of MY FRAM matrix to assess food safety risks in horticultural crops. Computers and Electronics in Agriculture, 114 . pp. 231-236. ISSN 0168-1699

It is advisable to refer to the publisher's version if you intend to cite from the work. http://dx.doi.org/10.1016/j.compag.2015.04.008

For more information about UCLan's research in this area go to http://www.uclan.ac.uk/researchgroups/ and search for < name of research Group>.

For information about Research generally at UCLan please go to http://www.uclan.ac.uk/research/

All outputs in CLoK are protected by Intellectual Property Rights law, including Copyright law. Copyright, IPR and Moral Rights for the works on this site are retained by the individual authors and/or other copyright owners. Terms and conditions for use of this material are defined in the policies page.

\section{CLoK}

Central Lancashire online Knowledge www.clok.uclan.ac.uk

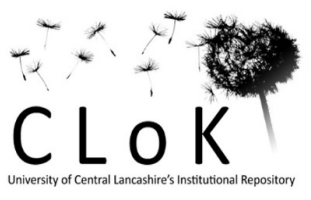




\section{Development of MY FRAM matrix to assess food safety risks in horticultural crops}

Soon, J. M. ${ }^{1}$ and Baines, R. N. ${ }^{2}$

${ }^{1}$ Faculty of Agro-Based Industry, Universiti Malaysia Kelantan, Jeli, Kelantan, Malaysia

${ }^{2}$ School of Agriculture, Royal Agricultural University, GL7 6JS, Gloucestershire, UK

\section{Corresponding author and author's addresses and emails:}

\section{Corresponding Author:}

${ }^{1}$ Jan Mei Soon

Faculty of Agro-Based Industry, Universiti Malaysia Kelantan, 17600 Jeli, Kelantan, Malaysia E-mail address: janmei.soon@yahoo.com; soon_jan@umk.edu.my

Tel: (+609) 9477107

Fax: (+609) 9477022

${ }^{2}$ Richard Baines

School of Agriculture, Royal Agricultural University, Cirencester, GL7 6JS, Gloucestershire, UK

E-mail address: richard.baines@rau.ac.uk

Tel: (+44) 01285652531 Ext: 2255

\section{Abstract}

A farm food safety risk assessment matrix (MY FRAM) was developed for horticultural farms.

The tool enables farmers to carry out self risk assessments on the potential of food safety risks on the farm from site selection to post-harvest handling. MY FRAM was developed on Microsoft ASP. NET C\# 4.5 with logical functions and utilised a semi-quantitative risk assessment approach (risk ranking of 1 -9) for farmers. MY FRAM is an illustrative risk ranking tool to allow farmers to quickly identify potential food safety risks and risk summary and corrective actions are suggested to farms on how to reduce the risks. The tool can also be utilised as a training tool for farm workers to understand the importance of food safety at the farm level. 


\section{Introduction}

35

36 Fresh produce and sprouted seeds have been implicated in a number of documented outbreaks of

37 illness in countries such as the US and within the EU. Powell and Chapman (2007) identified

38 that since 1990 there have been over 500 outbreaks related to produce in US and argued that

39 fresh fruits and vegetables are 'one of the most significant sources, if not the most significant

40 source of foodborne illness today'. The CDC reported that the incidence of outbreaks is greater

41 for vegetables than for fruits and revealed salad greens, lettuce, sprouts, melons and tomatoes as

42 the leading vehicles of illness. These fresh products have also received much attention by the

43 FAO/WHO, which gave leafy green vegetables (including fresh herbs) the highest priority as

44 commodities of global concern. Many of these commodities are vulnerable to contamination

45 because they grow on or close to soil where contamination can potentially occur. Produce can

46 also become contaminated with microbial pathogens by a wide variety of mechanisms.

47 Contamination leading to foodborne illness has occurred during production, harvest, processing,

48 and transporting, as well as in retail and foodservice establishments and in the home kitchen

49 (FDA, 2010).

50

51 The likelihood of the edible parts of a crop becoming contaminated depends upon a number of

52 factors which includes growing location, type of irrigation application and nature of produce

53 surface. Some of the sources of pre-harvest contamination of produce include irrigation water

54 (Steele and Odumeru, 2004), contaminated manure, sewage sludge, run-off water from livestock

55 operations and wild and domestic animals (Beuchat, 2006; Delaquis,Bach and Dinu, 2007). 
57 It is imperative to start reducing risk factors at farms, so this may reduce the contamination load

58 into the processing and food preparation stage. A farm food safety risk assessment may be one of

59 the many intervention strategies in reducing or preventing the food safety and disease risks from

60 occurring. Hence, the development of MY FRAM is timely and can be utilised by horticultural

61 farmers to identify potential food safety risks and to develop action plans or corrective actions.

62

63

2. Methods

$64 \quad 2.1 \quad$ Development of MY FRAM matrix

$65 \quad$ 2.1.1 User interface

66

67 MY FRAM was developed using Microsoft ASP. NET C\# 4.5 version framework and utilised

68 standard mathematical and logical functions to calculate the risks. The database portion was

69 handled using Microsoft SQL Server 2014 Express edition. To ease the development, Microsoft

70 Language Integrated Query, or better known as LINQ was used to establish the connection

71 between web application and database. On top of that, Microsoft AJAX Control Toolkit was also

72 used to enable asynchronous communication between certain functions in MY FRAM to enhance

73 users' experience. Users can go to http://umk.applyit.com.my and click on "Sign up new

74 account” to register. Once registered as user, user can select go to Project > Create Project. Users

75 are then prompt to name and describe the project. When a project has been created successfully,

76 user will be allowed to add new Study into the project based on a period of time. After naming

77 the study, users can go through the process to assess the risks for their crops. 
79 The development and improvement of the MY FRAM matrix is similar to the Level 1 risk

80 ranking proposed by van Gerwen et al. (2000) and the spreadsheet model of Soon et al. (2013)

81 and Ross and Sumner (2002) but it estimates the risks according to the farm process flow (e.g.

82 from site selection to harvest).

83

\section{$84 \quad 2.2 \quad$ Delphi-based approach}

\section{$85 \quad$ 2.2.1 Sampling and selection of experts}

86

87 Expert panels were invited (Valeeva, Meuwissen, Oude Lansink, \&Huirne, 2005) to take part in

88 the Delphi study to identify and select the most relevant food safety hazards (and diseases)

89 occurring at the fresh produce farms in UK. Here, the panellists were not selected randomly, so

90 representativeness is not assured. The selection of experts for the Delphi study was made

91 through:

92

- Personal contacts of the author and the research supervisory committee made in the course of the farm food safety research

- Participants in international food safety conferences

- Experts co-nominated by others (Scapolo\&Miles, 2006)

98 A total of 86 experts on fresh produce safety were contacted and invited to participate in the reduced response rates is typical of Delphi studies as carried out by Grundy and Ghazi (2009),

101 Stark et al. (2002) and Wentholt et al. (2010). 
102 Experts were defined as having met two criteria: (1) currently teaching in a university level food

103 science or agriculture/horticulture programme or working in the horticulture/agriculture (2)

104 experience in the food safety, microbiology, chemical, toxicology, or risk assessment. The

105 invitation contained a cover letter of a short description of the study and Delphi Round II

106 questionnaire. Even though it is more advantageous to conduct a face to face interview in the

107 first round to increase the response rates, it was not conducted in this study due to the limited

108 financial resources and time. Three rounds of questions and answers were deemed to be optimal

109 for this study (Soon et al. 2012):

110

111 Round (I) Review and collate potential farm food safety hazards occurring in fresh produce farms

Experts’ ranking of food safety hazards

Review feedback from Round II (and revise if necessary), review MY FRAM and suggest for improvements

\section{$117 \quad 2.3 \quad$ Testing of MY FRAM matrix on farms}

118 MY FRAM (spreadsheet version; Soon et al. 2013) was tested in 12 UK fresh produce farms.

119 The on-farm visit was conducted in 4 steps and a total duration of 3 hours was targeted. Steps 120 included (i) interview with the farmer or technical/farm manager to gather farm food safety 121 practices data, (ii) briefing and explanation of MY FRAM, (iii) Testing of MY FRAM and 122 collecting feedback from farms, and (iv) tour of farm and facilities with farmer.

\section{$124 \quad$ 3. Results and Discussion}




\subsection{Good Agricultural Practice (GAP) analysis}

126 Most risk based models and standards for managing food safety at the farm level rely on the 127 adoption of Good Agricultural Practice (GAP), therefore MY FRAM matrix required appropriate

128 GAP to be embedded. The Good Agricultural Practice (GAP) Analysis self-assessment questions 129 were developed for fresh produce production to encourage farmers to assess specific process 130 during the primary production. A check-list containing 38 questions was drawn up according to 131 Good Agricultural Practice (with an emphasis on food safety) and distributed under 8 sections 132 according to the production process and inputs: (1) Process - Site selection; (2) Process 133 Seed/transplants; (3) Process - Sowing/planting; (4) Process - Crop harvest; (5) Process - Post134 harvest handling; (6) Input - Irrigation water (Figure 1); (7) Input - Fertilizers and (8) Input 135 Pesticides (Knight 2009; Rangarajan et al. 2000). Figure 1 shows a snapshot of the self136 assessment based on Good Agricultural Practices. Figure 1 does not illustrate GAP but was 137 designed in a question and answer format to allow farmers to conduct their own self risk 138 assessment of their current farm situation. These 38 questions were drawn up based on 139 commercial systems such as GlobalGAP, Tesco Leafy Crop Assessment, Safeproduce.eu and 140 FDA Produce Rule. The questions were selected on the basis of occurrences of potential hazards 141 at the farm level and these 38 questions were summarised in order to allow farmers to focus on 142 basic fresh produce safety criteria. A number of questions ( $>40)$ may be too distracting for the 143 farmers, while too few questions may not provide enough resolution for the farmers to conduct 144 appropriate self-assessments. A more comprehensive and shorter version of assessment questions 145 is more suited for small and medium farmers to enable them to focus their resources in 146 prioritising food safety. 


\subsection{Process Flow}

151 MY FRAM is then divided into different process flow ranging from site selection to postharvest 152 handling and inputs such as irrigation water, application of fertilisers and pesticides. According 153 to the processes, users are given scenarios of likelihood of occurrences (high, medium, low or no 154 defined risk) to select from. For example, the risk factor for irrigation water sources is described. 155 The low likelihood of occurrence for potential hazards to arise is defined as fresh produce farms 156 using borehole/ground water or using tested (safe) surface water while higher likelihood of 157 occurrence of food safety problems is associated with the use of surface water (Figure 2) with 158 possible livestock access.

162 Farmers use MY FRAM based on their own judgment while assessing the likelihood of 163 occurrences. Examples are given to enable users to select and determine the likelihood of 164 selected/certain food safety hazards that could occur on their farms.

165 Risks are assessed on the probability of future occurrence; how likely is the risk to occur? 166 How frequently has this occurred? (HSE 2008) Likelihood of occurrence is divided into low (1), 167 medium (2) and high (3).

169 The criteria to help farmers to assess the likelihood of occurrence are:

(3): This hazard has caused outbreak/recall on my farm 

178 industry experts.
Medium

Low

The severity scoring is based on the following parameters (for general population unless

181 stated otherwise):

182

(2): This outbreak/contamination has been reported in the local media or had occurred in other nearby farms

(1): Never occurred, but likelihood of occurrence is possible

\subsection{Severity of food safety hazard}

Criteria for the definition of each level of severity scoring for each risk factor were based on the review of literature and food legislation, vetted by consensus expert opinion from academia and

Minor : Minor injury to consumer

Moderate $\quad$ : Consumer in hospital/Serious short term injury

High : May lead to severe health impact or death

\subsection{Risk weight (severity $\times$ likelihood)}

A risk matrix is developed to measure risk. The determination of risk is derived by multiplying the scores assigned for likelihood of occurrences and the severity of the hazards. The risk matrix consists of a 3 x 3 matrix of likelihood (high, medium and low) and severity (high, medium and low) to keep the risk assessment as simple as possible for farm operators' usage (Figure 3). There are other matrixes which use 4 x 4 or a 5 x 5 matrix depending on the risk assessor's requirements. According to Moses and Malone (2005), a typical 3 x 3 matrix do not provide 
enough resolution, while anything greater than a $5 \times 5$ was too distracting. This $3 \times 3$ matrix is

194 adopted for its simplicity in translating practical risk ranking outputs for farm personnel.

196 The overall food safety risk can be categorised into high, medium or low based on the risk 197 ranking score (1-9) when likelihood score multiplies with severity score. The scores used in 198 FRAM matrix were based on a simple 1 to 9 scoring system to retain simplicity.

Figure 3. Food safety risk (Risk weight) $=$ Likelihood of occurrence $\times$ Severity of food safety

\subsection{Results presentation}

206

207 The farm food safety risk assessment results is summarised in a tabular and radar format (Figure 208 4). First, the likelihood assessments are scored by the users based on their experiences and farm 209 specificity. The relative ranking of risk scores will help farms to prioritise and optimize the 210 allocation of resources or to request for technical assistance to reduce the likelihood of food 211 safety hazards and diseases from occurring. However, the risk scores generated by the MY 212 FRAM should be interpreted with caution. This is due to the generic nature of the tool and 213 uncertainty associated with risks.

Figure 4. Example of results shown in radar chart format 


\section{$217 \quad 3.6 \quad$ Development of action plan and control measures}

218 From the risk ranking output, farmers are then guided to develop their own action plan for

219 improvement and control measures (Figure 5) are suggested according to Good Agricultural 220 Practices section (HSE 2006; Knight 2009).

221

Figure 5. Action plan and corrective actions

\section{$224 \quad 3.7 \quad$ Effectiveness as judged by the end user}

225 End users (farmers) were asked to determine which part of the tool and topics were most useful 226 or relevant to them. Developing their own action plan and using it as proof of assessment for 227 future third-party audits were ranked the highest among the farms (Fig. 6). All the farms also 228 agreed that 'Sowing/Planting' and 'Irrigation Water' topics were the most relevant and useful to 229 them followed by 'Plant Protection Products' (92\%) and 'Harvesting' (92\%). A few topics such 230 as waste handling and on-site packing (e.g. harvesting and bagging of fresh produce on rigs)

231 were suggested to be included into MY FRAM. Farm B also stated that there should be less 232 focus on wild animals’ assessment. Instead, more emphasis should be given to pesticides 233 assessment as well as to expand the post-harvest handling assessment into individual washing, 234 grading and packing assessments. Farm $C$ noted that MY FRAM should specify the type of 235 crops and risks of specific crops, e.g. Group I - leafy greens, tomatoes; Group II - carrots, 236 onions; Group III - potatoes and Group IV - wheat, sugarbeet. More than half of the farms 237 (58\%) revealed that MY FRAM matrix has increased their interest in conducting farm food 
238 safety-risk assessment and 45\% stated that after testing and using MY FRAM, it has improved

239 their farm-food safety practices knowledge.

241 Figure 6. Most useful / relevant part of MY FRAM matrix (n=11 farms)

$243 \quad$ 4. Role of MY FRAM in horticultural crops

244 The semi-quantitative scoring system of MY FRAM matrix to characterise risk is a good 245 approach to help growers to understand that certain practices can be dangerous (e.g. surface 246 water accessible by livestock). MY FRAM matrix can provide growers with a simpler means of 247 assessing the level of produce safety in their farm based on general GAP requirements. Industry 248 and/or commodity specific audits are extensive and costly and guidance from tools such as MY 249 FRAM, Safeproduce.eu (http://www.safeproduce.eu/Login.aspx?ReturnUrl=\%2fDefault.aspx) 250 and the proposed rule for Standards for the Growing, Harvesting, Packing, and Holding of

251 Produce for Human Consumption (FDA, 2014) will facilitate farmers in identifying potential risk 252 factors. The choice of food safety risk assessment model / matrix / tool is crucial to an 253 organisation and MY FRAM can be utilised as a mechanism for assessing food safety risks and 254 is an optional choice of self-risk assessment for farmers (Manning and Soon, 2013).

\section{$256 \quad 5 . \quad$ Limitations of MY FRAM}

257 The general GAP requirements will be similar for all farms but some growers will require a more 258 specialised GAP approach depending on their commodity or target consumers. In order to keep 259 MY FRAM simplistic and to encourage farmers to carry out self-risk assessments; some of the 260 risk factors were not specific enough and options given were limited, e.g. under risk factor for 
261 site selection: 'Probability of site contaminated with run-offs from livestock farms'. Three

262 scenarios likelihood of occurrences were given: (i) My farm is upstream from any sources of

263 contamination; (ii) My farm is downstream from a well-managed livestock farm but may receive

264 run-off during flooding; and (iii) My farm is downstream from at least one livestock farm and

265 run-offs are commonly received. Since different farms faced different geographical

266 environments, the options or scenarios given may not be specific enough for farms to select

267 from. Hence this causes the farms to prompt further 'what if' questions - such as 'What if I'm

268 using borehole water and my neighbouring farm is a well-contained livestock farm?' When using

269 MY FRAM, farmers are provided with a guide to determine the level of risks involved in

270 different processes.

271

$272 \quad$ 6. Conclusion

273 MY FRAM matrix can be described as an illustrative risk ranking tool to facilitate horticultural

274 farmers to identify potential risk factors during their crop production. It is best suited for small

275 and medium enterprises (SMEs) to encourage farmers to identify food safety hazards and to help

276 develop appropriate action plan for improvement. MY FRAM is a combination of semi-

277 quantitative (matrix) and value-based criteria (based on farmers’ judgement of likelihood and

278 experiences) to assess risks. An on-farm food safety risk assessment tool may be timely to 279 encourage farms to assess potential hazards and to train both full-time and seasonal farm 280 workers. MY FRAM focuses on risk reduction and not risk elimination.

281

\section{Acknowledgement}


283 The authors gratefully acknowledge the financial support from the Ministry of Education

284 Malaysia (R/RAGS/A07.00/00295A/001/2013/000120). The funder played no role in study

285 design, collection, analysis, interpretation of data, writing of the report or in the decision to

286 submit the paper for publication. 


\section{References}

288

289

290

291

292

293

294

295

296

297

298

299

300

301

302

303

304

305

306

307

308

309

310

Beuchat, L.R. (2006) Vectors and conditions for preharvest contamination of fruits and vegetables with pathogens capable of causing enteric diseases. British Food Journal 108(1): 38-53

Delaquis, P., Bach, S. and Dinu, L.-D. (2007) Behavior of Escherichia coli O157:H7 in leafy vegetables. Journal of Food Protection 70(8): 1966-1974

FDA (1998) Guidance for industry: Guide to minimize microbial food safety hazards for fresh fruits and vegetables [online]. Available from: http://www.fda.gov/Food/GuidanceComplianceRegulatoryInformation/GuidanceDocu ments/ProduceandPlanProducts/ucm064574.htm [Date accessed: 23.6.10]

FDA (2014) Standards for the Growing, Harvesting, Packing, and Holding of Produce for Human Consumption [online]. Available from: http://www.regulations.gov/\#!documentDetail;D=FDA-2011-N-0921-0973 [Date accessed: 4.11.14]

FDA (2010) Chapter IV. Outbreaks Associated with Fresh and Fresh-Cut Produce. Incidence, Growth, and Survival of Pathogens in Fresh and Fresh-Cut Produce. [online]. Available from: http://www.fda.gov/Food/ScienceResearch/ResearchAreas/SafePracticesforFoodProc esses/ucm091265.htm [Date accessed 15.3.10]

Grundy, M. and Ghazi, F. (2009) Research priorities in haemato-oncology nursing: Results of a literature review and a Delphi study. European Journal of Oncology Nursing 13(4): 235-249.

HSE (2006) Five steps to risk assessment. Health and Safety Executive [online] 87:405-420. Available from: http://www.hse.gov.uk/risk/fivesteps.htm [Date accessed 22.6.10] 
311

312

313

314

315

HSE (2008) Risk assessment tool and guidance (Including guidance on application) [online] Available from: http://www.hse.ie/eng/About/Who/OQR012_20081210_v4_Risk_Assessment_Tool_ and_Guidance_incl_guidance_on.pdf [Date accessed 3.1.11]

Knight, C. (2009) Guideline no. 10, HACCP in agriculture: a practical guide. $3^{\text {rd }} \mathrm{ed}$. Campden BRI.

LGMA (2010) Commodity specific food safety guidelines for the production and harvest of lettuce and leafy greens. [online] Available from: http://www.caleafygreens.ca.gov/members/documents/LGMAAcceptedFoodSafetyPr actices01.29.10.pdf [Date accessed: 13.8.10]

Manning, L. and Soon, J. M. (2013) Mechanisms for assessing food safety risk. British Food Journal 115: 460-484.

Moses, K. D. and Malone, R. W. Jr. (2005) Development of risk assessment matrix for NASA Engineering and Safety Center. [online] Available from: http://ntrs.nasa.gov/archive/nasa/casi.ntrs.nasa.gov/20050123548_2005093494.pdf [Date accessed 23.2.10]

Powell, D. and Chapman, B. (2007) Fresh threat: what is lurking in your salad bowl. Journal of Science, Food and Agriculture 87: 1799-1801

Rangarajan, A., Bihn, E. A., Gravani, R. B., Scott, D. L. and Pritts, M. P. (2000) Food safety begins on the farm. A grower's guide. Good Agricultural Practices for fresh fruits and vegetables. [online] Available from: http://ecommons.cornell.edu/handle/1813/2209?mode=full [Date accessed: 4.1.11]

Ross, T. and Sumner, J. (2002) A simple, spreadsheet-based, food safety risk assessment tool. International Journal of Food Microbiology 77(1-2):39-53.

Soon, J. M., Davies, W. P., Chadd, S. A. and Baines, R. N. (2012). A Delphi-based approach 
to developing and validating a farm food safety risk assessment tool by experts. Expert Systems with Applications 39(9): 8325-8336.

Soon, J. M., Davies, W. P., Chadd, S. A. and Baines, R. N. (2013). Field application of farm food safety risk assessment (FRAMp) tool on small and medium fresh produce farms. Food Chemistry 136(3-4): 1603-1609.

Stärk, K. D. C., Wingstrand, A., Dahl, J., Møgelmose, V. and Lo Fo Wong, D. M. A. (2002) Differences and similarities among experts’ opinions Salmonella enterica dynamics in swine pre-harvest. Preventive Veterinary Medicine 53: 7-20.

Steele, M. and Odumeru, J. (2004) Irrigation water as source of foodborne pathogens on fruits and vegetables. Journal of Food Protection 67(12): 2839-2849.

Suslow, T, Oria, M. P., Beuchat, L. R., Garrett, E. H., Parish, M. E., Harris, L. J., Farber, J. N. and Busta, F. F. (2003) Production practices as risk factors in microbial food

van Gerwen, S. J. C., te Giffel, M. C., van 't Riet, K., Beumer, R. R. and Zwietering, M. H. (2000) Stepwise quantitative risk assessment as a tool for characterization of microbiological food safety. Journal of Applied Microbiology 88: 938-951.

Wentholt, M. T. A., Rowe, G., König, A., Marvin, H. J. P. and Frewer, L. J. (2009) The views of key stakeholders on an evolving food risk governance framework: Results from a Delphi study. Food Policy 34: 1731-1738.

WHO (1989) Health guidelines for the use of wastewater in agriculture and aquaculture. Technical Report Series, No. 778) 


\section{$362 \quad$ Figure Captions}

363 Figure 1. Self-Risk Assessment (Question and Answer format) of Good Agricultural

364 Practices

365 Figure 2. Example of likelihood scoring for 'source of irrigation water'

366 Figure 3. Food safety risk (Risk weight) $=$ Likelihood of occurrence $\times$ Severity of food safety

367 hazard

368 Figure 4. Example of results shown in radar chart format

369 Figure 5. Action plan and corrective actions

370 Figure 6. Most useful / relevant part of MY FRAM matrix (n=11 farms)

371

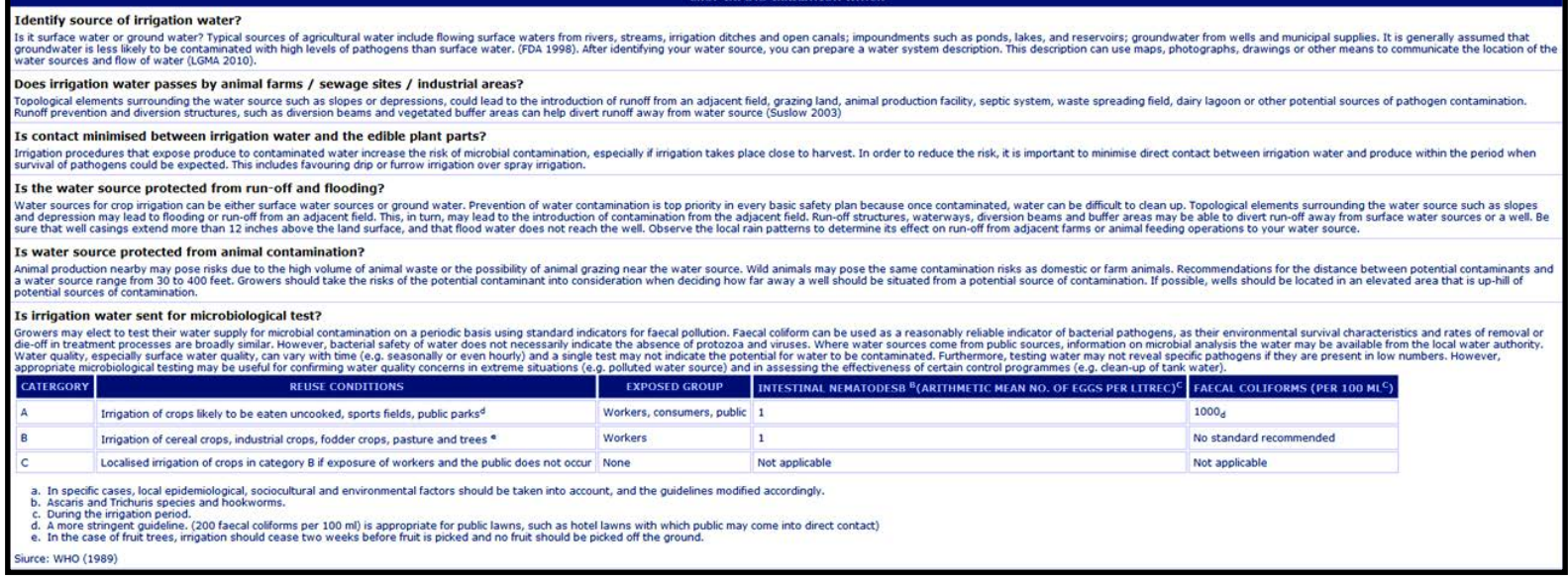

Figure 1. Self-Risk Assessment (Question and Answer format) of Good Agricultural

Practices 


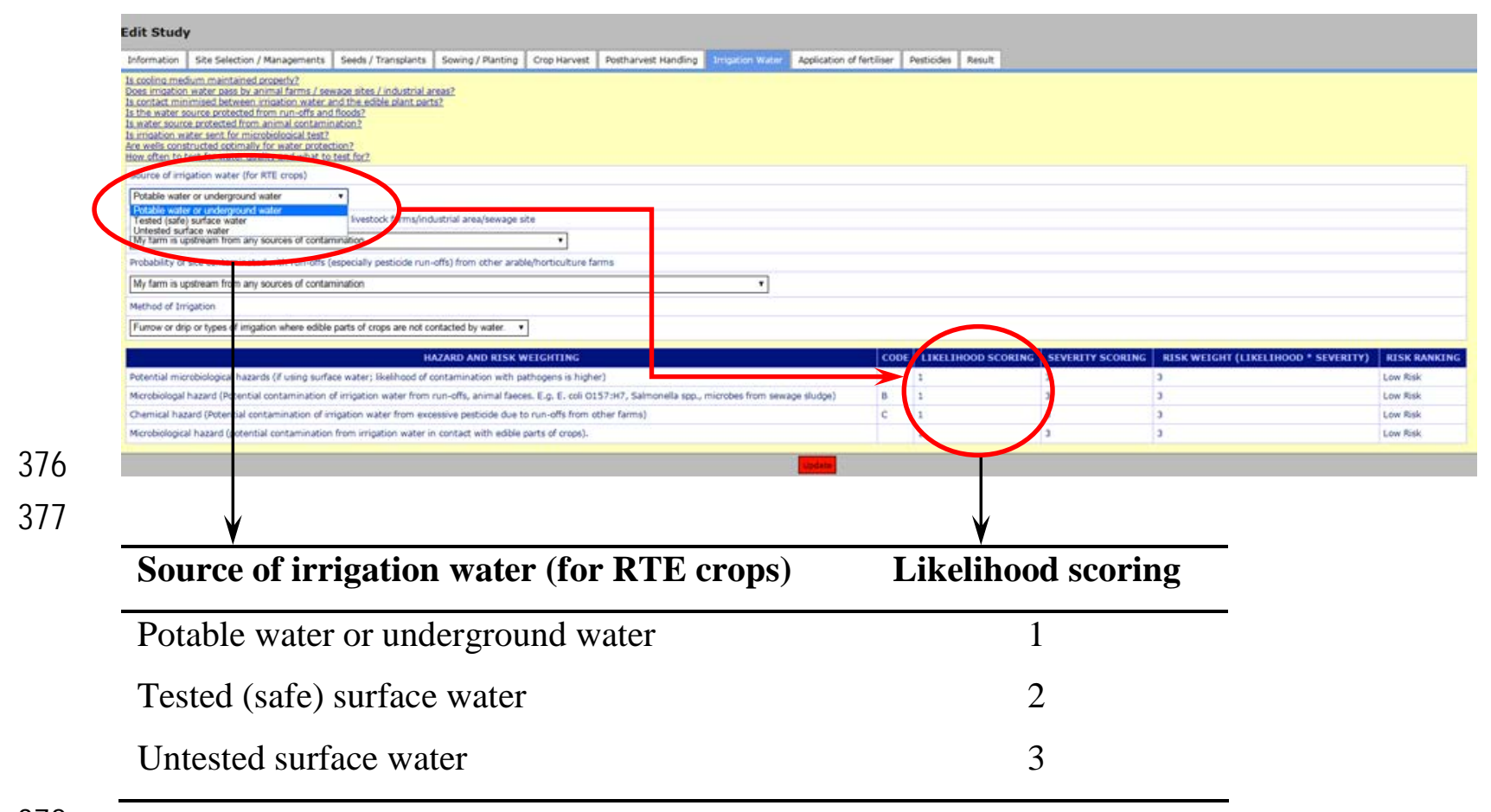

Figure 2. Example of likelihood scoring for 'source of irrigation water'

\begin{tabular}{lccccc}
\hline $\begin{array}{l}\text { Source of irrigation } \\
\text { water (for RTE } \\
\text { crops) }\end{array}$ & Likelihood scoring & $\begin{array}{c}\text { Severity } \\
\text { scoring }\end{array}$ & $\begin{array}{c}\text { Likelihood } \\
\text { x severity } \\
\text { scoring }\end{array}$ & $\begin{array}{c}\text { Risk } \\
\text { weight }\end{array}$ & $\begin{array}{c}\text { Risk } \\
\text { ranking }\end{array}$ \\
\hline $\begin{array}{l}\text { Potable water or } \\
\text { underground water } \\
\begin{array}{l}\text { Tested (safe) surface } \\
\text { water }\end{array}\end{array}$ & 1 & 3 & $1 \times 3$ & 3 & $\begin{array}{c}(1-3) \\
\text { low }\end{array}$ \\
$\begin{array}{l}\text { Untested surface } \\
\text { water }\end{array}$ & 2 & 3 & $2 \times 3$ & 6 & $\begin{array}{c}(4-6) \\
\text { medium } \\
(6-9) \\
\text { high }\end{array}$ \\
\hline
\end{tabular}

Figure 3. Food safety risk (Risk weight) $=$ Likelihood of occurrence $\times$ Severity of food safety 


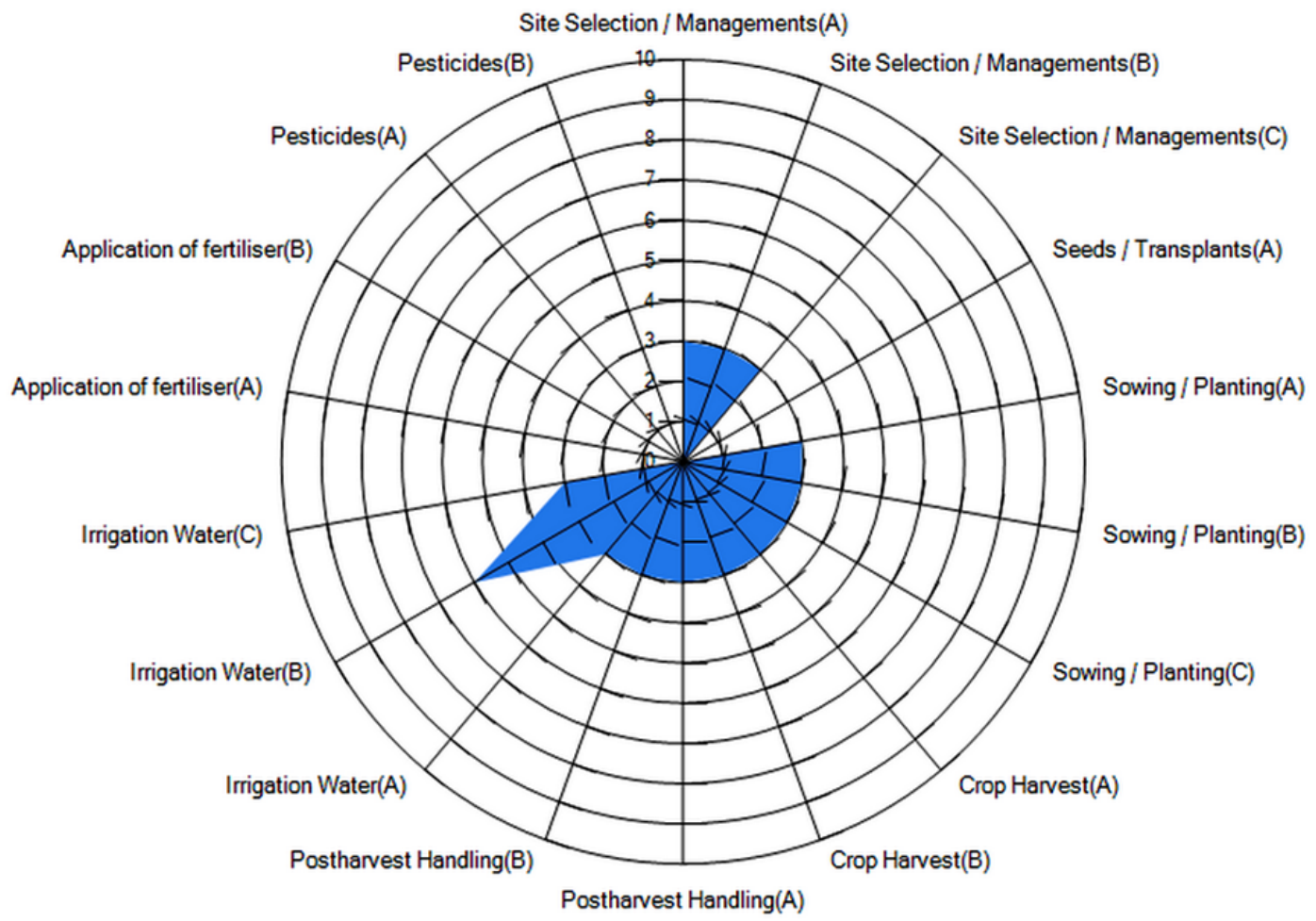

Postharvest Handling(A)

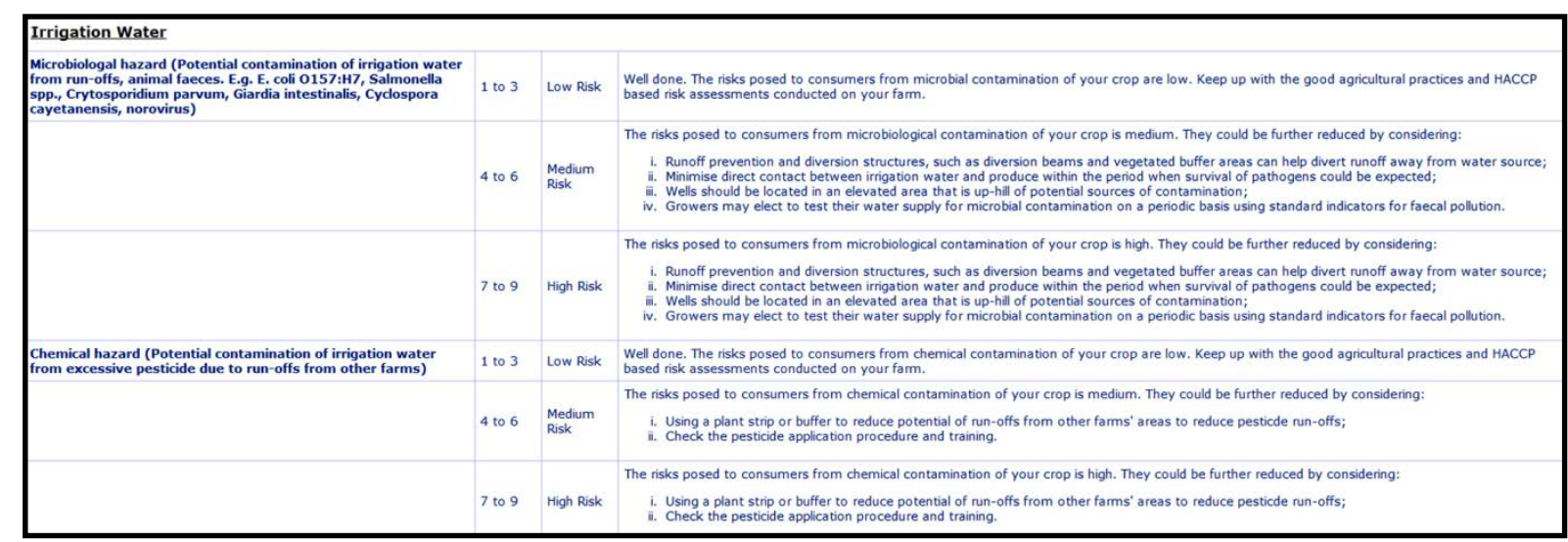




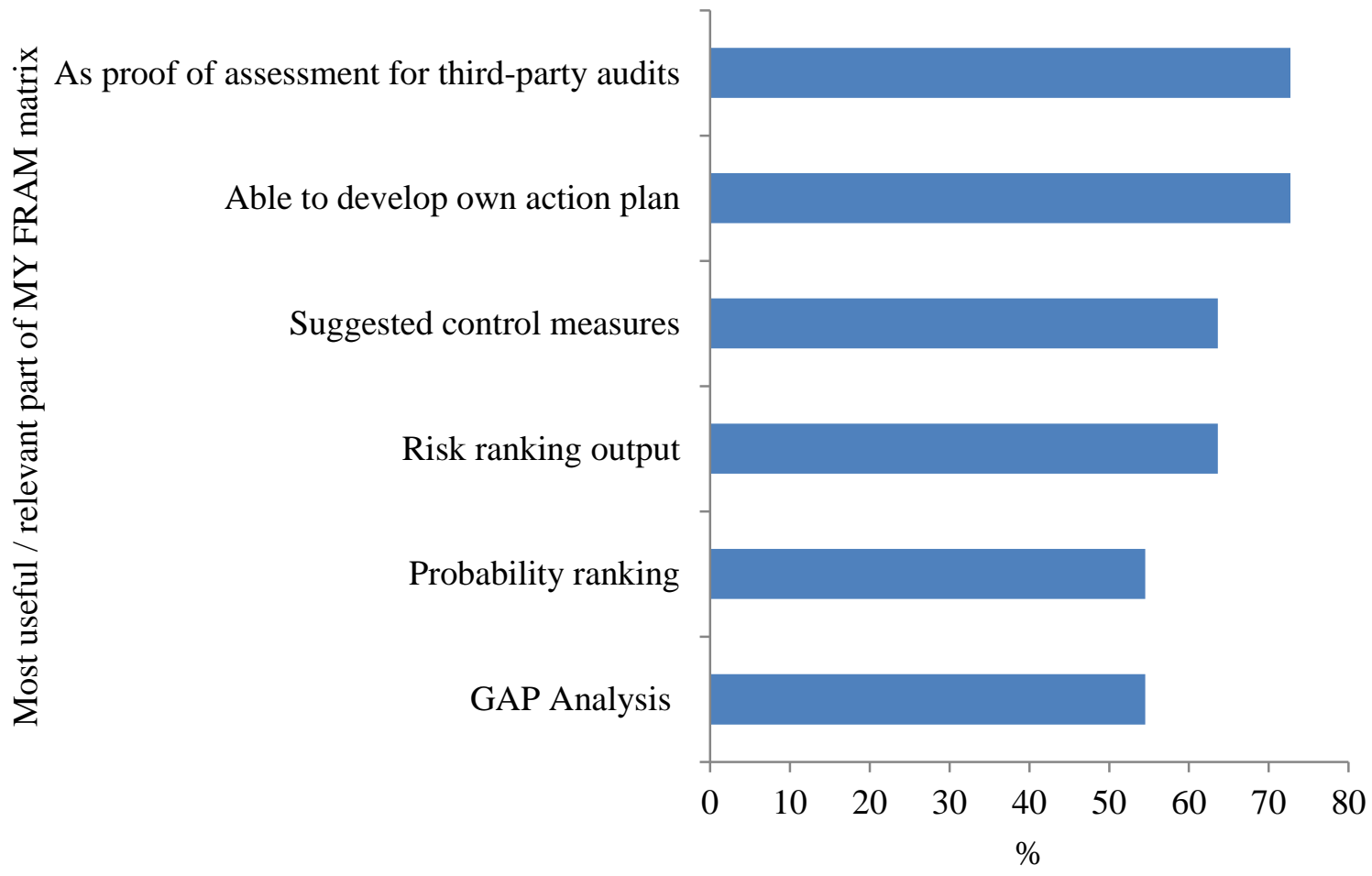

